MATEC Web of Conferences 25, 01004

(2015)

DOI: $10.1051 /$ matec conf/ 20152501004

(c) Owned by the authors, published by EDP Sciences, 2015

\title{
Response of Fresh Water Distributions on Abrupt Changes of Topography in the Pearl River Networks of China
}

\author{
Shousheng $\mathrm{Mu}^{*}$, Yong He, Zhenjun $\mathrm{He} \& \mathrm{Bo} \mathrm{Su}$ \\ The Pearl River Hydraulic Research Institute, Guangzhou, Guangdong, China \\ Key Laboratory of the Pearl River Estuarine Dynamics and Associated Process Regulation Ministry of Water \\ Resources, Guangzhou, Guangdong, China
}

\begin{abstract}
A 2-D numerical model was used to study the response of fresh water transports and distributions on the abrupt changes of topography in the Pearl River Networks (RNPRD). The results indicate that both the tidal forces in Jiaomen and Humen and the runoff power in Modaomen are intensified, which leads to a fresh water movement from the northeast to the southwest side of the West and North River Delta Networks. However, the water distributions in the East River Delta Networks remain almost the same. The residual currents in the RNPRD decreased dramatically in the West and North River Delta Networks due to the increasing volume of the river channels. This decreasing trend was intensified in the North River Main Channel due to the annual water discharge redistribution in the RNPRD.
\end{abstract}

Keywords: water distributions; numerical model; the Pearl River networks

\section{INTRODUCTION}

The Pearl River Network (RNPRD) is the world's most complicated tidal river network system located in the northern continental shelf of the South China Sea (CSC, Figure 1). Anthropogenic impacts such as sand excavation and waterway regulation have greatly changed the morphology of the Pearl River Delta (PRD), resulting in a severe and uneven river-bed down cutting in the entire Pearl River Network (RNPRD) during the past 20 years. Luo et al. (2007) report that more than $7 \times 10^{7} \mathrm{~m}^{3} / \mathrm{yr}$ of river sand has been dredged from all of the 324 tributaries of the RNPRD during 1986 to 2003, resulting in average down cutting depths of $0.59-1.73 \mathrm{~m}$ in West River, $0.34-4.43 \mathrm{~m}$ in North River and $1.77 \mathrm{~m}-6.48 \mathrm{~m}$ in East River (three major water networks in the RNPRD). It is seven times more than the average amount of sedimentation before the sand mining began. Uncontrolled sand excavation changed the hydrodynamic significantly, which leads to an increased tidal prism and upstream movement of the tidal limit in the RNPRD (Zhang et al. 2010). Therefore, the fresh water transports and distributions in the RNPRD have also changed.

\section{STUDY AREA}

The Pearl River is the second longest river in china in terms of mean annual water discharge, and its delta area consists of a tidal river network (called the RNPRD) and an estuary (called the PRE). The RNPRD is mainly comprised of the West River, East River, North River and other tributaries (Figure 1). *Corresponding author: shoushengmhhu@126.com
These rivers repeatedly bifurcate after entering the Pearl River Delta and form an intricately interlaced network of narrow channels, which empty out though eight outlets (Humen, Jiaomen, Hongqimen, Hengmen, Modaomen, Jitimen, Hutiaomen and Yamen respectively form the eastern to western side of the PRE). The RNPRD's mean annual loads of water and sediments was $286 \times 10^{9} \mathrm{~m}^{3} / \mathrm{yr}$ and $75.3 \times 10^{9} \mathrm{~kg} / \mathrm{yr}$ (from 1957 to 2006), which is the second largest contributor of water and suspended sediments to the SCS.

In the mid-1980s, the large-scale and long-term sand excavation was initiated to meet the construction needs raised from the rapid economic growth and urbanization in this region. These unofficial and uncontrolled practices have accelerated the riverbed evolution process, altering the hydrodynamics of the entire river network (Luo et al. 2002). Thus concerns on the hydrodynamics of the Pearl River Delta have increased in recent years (Hu et al.2011; $\mathrm{Du}$ et al. 2014). However, little attentions have been paid to the possible changes of the fresh water transports and distributions in the RNPRD, which have severe impacts on the river channel's immediate vicinity, the estuary, and the coastal areas.

\section{METHODS}

\subsection{Model setup}

The RNPRD is characterized by one-dimensional flow while the PRE is a typical two-dimensional and three-dimensional flow (Du et al. 2014; $\mathrm{Hu}$ et al. 2009). Therefore, a 2-D numerical model covered the entire Pearl River Delta is applied to study the water

This is an Open Access article distributed under the terms of the Creative Commons Attribution License 4.0, which permits unrestricted use, distribution, and reproduction in any medium, provided the original work is properly cited. 


\section{MATEC Web of Conferences}

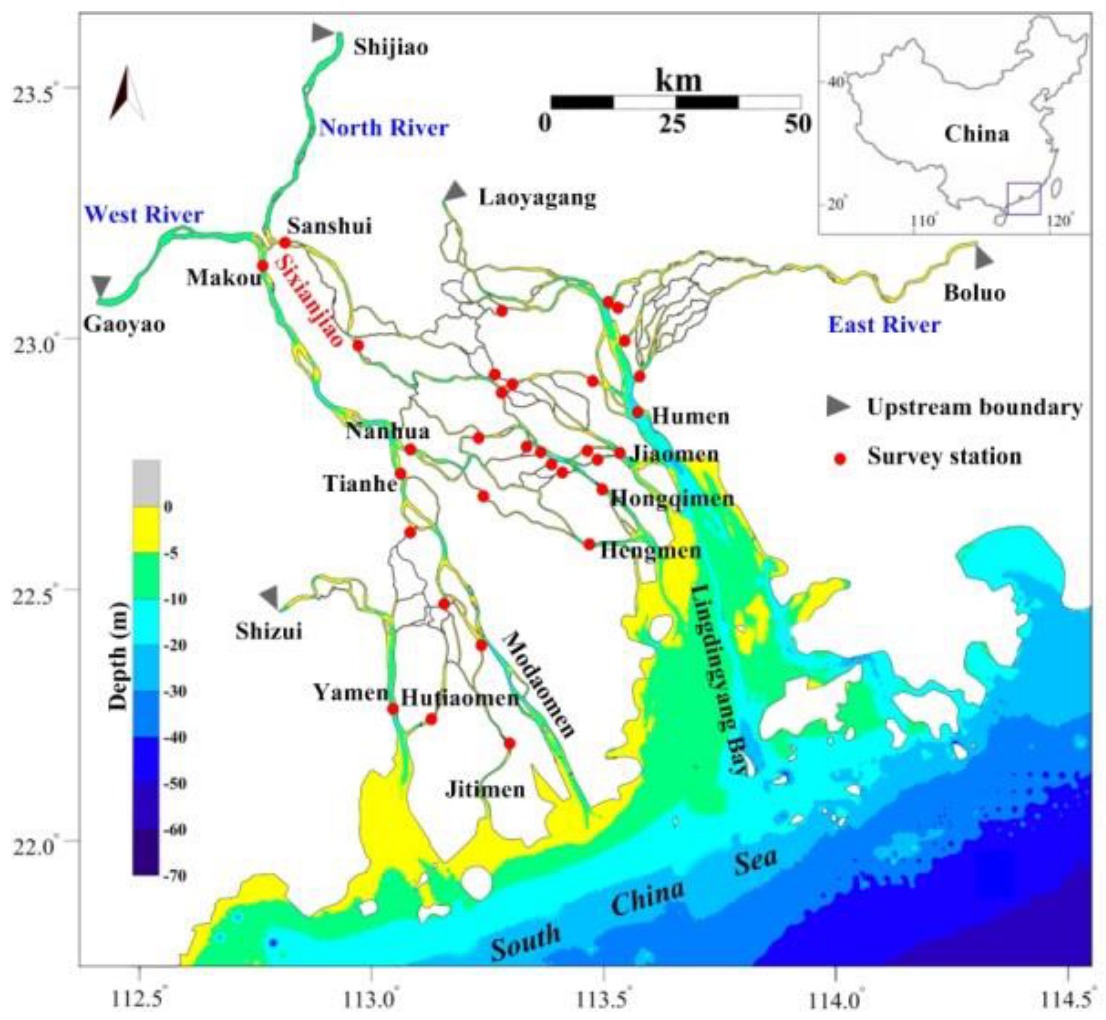

Figure 1. Map of showing the Pearl River Delta, bottom topography, major rivers and survey stations

and sediment transportation in different bathymetries. The depth-averaged 2-D hydrodynamic model was based on the 2-D shallow-water equations while depending on the Bousinesq eddy viscosity and static pressure hypothesis. The governing equations are expressed as Continuity equation:

$\frac{\partial h}{\partial t}+h\left(\frac{\partial u}{\partial x}+\frac{\partial v}{\partial y}\right)+u \frac{\partial h}{\partial x}+v \frac{\partial h}{\partial y}=0$

The momentum equation in the $\mathrm{X}$ direction:

$\frac{\partial h \bar{u}}{\partial t}+\frac{\partial h \bar{u}^{2}}{\partial x}+\frac{\partial h \bar{u} \bar{V}}{\partial y}=f \bar{v} h-g h \frac{\partial \eta}{\partial X}-\frac{h}{\rho_{0}} \frac{\partial P_{a}}{\partial X}-\frac{g h^{2}}{2 \rho_{0}} \frac{\partial \rho}{\partial X}+$

$\frac{\tau_{s x}}{\rho_{0}}-\frac{\tau_{b x}}{\rho_{0}}-\frac{1}{\rho}\left(\frac{\partial S_{x x}}{\partial x}+\frac{\partial S_{x y}}{\partial x}\right)+\frac{\partial}{\partial x}\left(h T_{x x}\right)+\frac{\partial}{\partial y}\left(h T_{x y}\right)+h u_{s} S$

The momentum equation in the $\mathrm{Y}$ direction:

$\frac{\partial h \bar{V}}{\partial t}+\frac{\partial h \bar{V}^{2}}{\partial y}+\frac{\partial h \bar{u} \bar{v}}{\partial x}=f \bar{v} h-g h \frac{\partial \eta}{\partial y}-\frac{h}{\rho_{0}} \frac{\partial P_{a}}{\partial y}-\frac{g h^{2}}{2 \rho_{0}} \frac{\partial \rho}{\partial y}+$

$\frac{\tau_{s y}}{\rho_{0}}-\frac{\tau_{b y}}{\rho_{0}}-\frac{1}{\rho}\left(\frac{\partial S_{y X}}{\partial x}+\frac{\partial S_{y y}}{\partial y}\right)+\frac{\partial}{\partial x}\left(h T_{x y}\right)+\frac{\partial}{\partial y}\left(h T_{y y}\right)+h V_{s} S$

Where $\mathrm{t}$ is the time; $\mathrm{u}$ and $\mathrm{v}$ are the vertically averaged velocities in $\mathrm{x}$ and $\mathrm{y}$ directions; $\mathrm{h}$ is the total water depth; $\eta$ is the water level relative to calculate level; $P_{a}$ is the air pressure; $f=2 \Omega \sin \phi$ is cor- iolis parameter $\left(\Omega=0.729 \times 10^{-4} s^{-1}\right) ; f \bar{u}$ and $f \bar{v}$ are the accelerated velocities caused by earth rotation; $T_{x x}, T_{x y}, T_{y x}, T_{y y}$ are components of viscous stress; $S$ is component of sources; $s_{x x}, s_{x y}, s_{y x}$ and $s_{y y}$ are the stress of radiation.

Table 1. Main parameters of the model

\begin{tabular}{|c|c|c|}
\hline \multicolumn{2}{|c|}{ Model parameter description } & Unit \\
\hline $\begin{array}{l}\text { Upstream bound- } \\
\text { ary }\end{array}$ & Hourly measured discharge & $\mathrm{m}^{3} / \mathrm{s}$ \\
\hline Coastal boundary & $\begin{array}{l}\text { Hourly water level from } \\
\text { tidal wave predicition mod- } \\
\text { el }\end{array}$ & $\mathrm{m}$ \\
\hline Time step & 30 & $\mathrm{~s}$ \\
\hline Terrain conditions & $\begin{array}{l}\text { Measured data of } 1999 \text { and } \\
2005\end{array}$ & $\mathrm{~m}$ \\
\hline Bed roughness & $0.015 \sim 0.030$ & - \\
\hline Eddy viscosity & 0.28 & - \\
\hline Initial conditions & $\begin{array}{l}\text { water level on each grid } \\
\text { node }\end{array}$ & $\mathrm{m}$ \\
\hline
\end{tabular}

Considering the complex geometry of the study area, an unstructured grid covering the entire PRD was 
developed, which was specially refined in the RNPRD. The coastal boundary is extended to $-30 \mathrm{~m}$ isobaths, while the upstream boundaries respectively stretch to Gaoyao in West River, Shjiao in North River, Boluo in East River, Layagang in Liuxi River and Shizui in Tanjiang River (Figure 1). The main parameters of model are shown in Table1.

\subsection{Model calibration and validation}

The model was tested by two representative periods, including July 16-24 1999 (wet season) and February 7-16 2001 (dry season). The comparisons of model results and measurements of water level, discharge for part of the survey stations are shown in Figure 2. The domain mean error and relative error of the total 32 stations are shown in Table 2 (the locations of the survey stations are seen in Figure 1.). The results of model validation are in reasonable agreement with the measured data, which indicate that the model is robust enough to review the fresh water transportations in the RNPRD. Special information regarding the model calibration and validation were also described in detail by $\mathrm{Du}$ and $\mathrm{Mu}$ (2014). The hydrodynamic model calculates the fresh water transportations in 2003 under the bathymetry conditions of 1999 and 2005 respectively.

Table 2. Main parameters of the model

\begin{tabular}{lllll}
\hline \multicolumn{2}{l}{ Simulation period } & $\begin{array}{l}\text { Mean } \\
\text { error }\end{array}$ & $\begin{array}{l}\text { Relative } \\
\text { error \% }\end{array}$ & $\mathrm{r}^{2}$ \\
\hline February & Water level & -0.03 & -5.0 & 0.95 \\
2001 & Discharge & 60.0 & 10.3 & 0.89 \\
\multirow{2}{*}{ July 1999 } & Water level & -0.08 & -4.6 & 0.98 \\
& Discharge & 182.0 & 8.6 & 0.91 \\
\hline
\end{tabular}

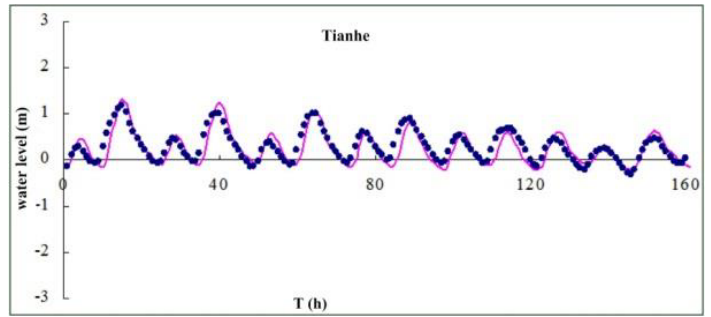

(1)

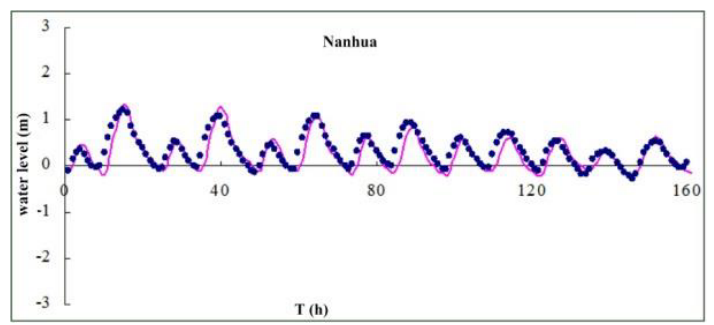

(2)

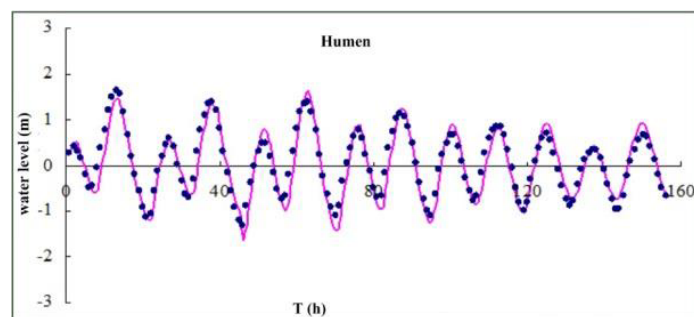

(3)

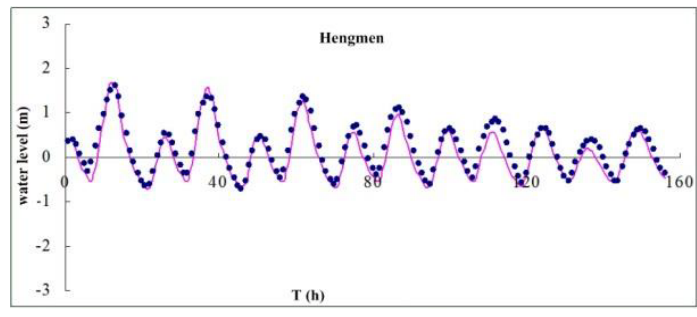

(4)

Figure 2a. Calibration of water level for dry season (solid line signifies model results and points depict observations)

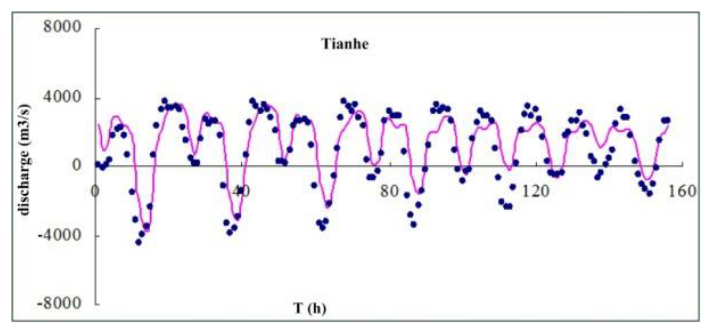

(1)

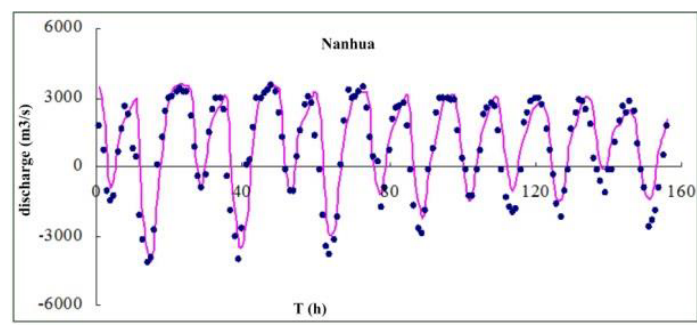

(2)

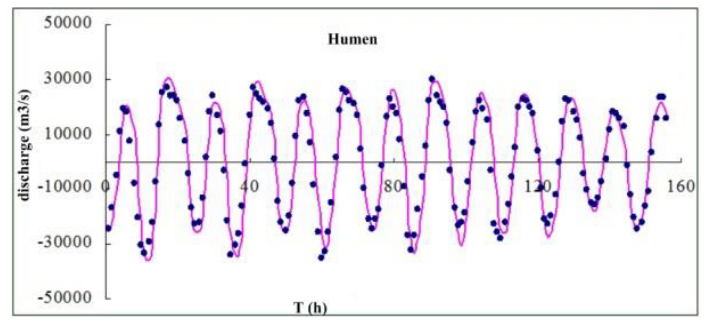

(3) 


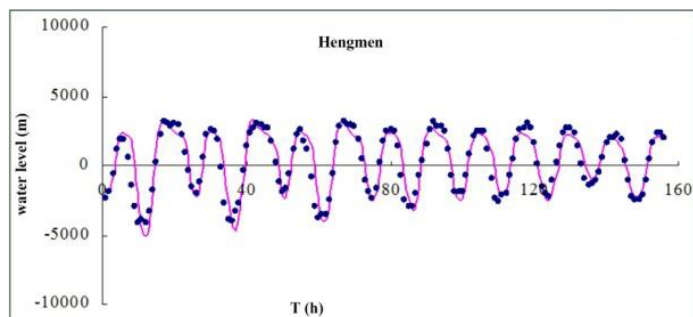

(4)

Figure 2b. Calibration of discharge for dry season (solid line signifies model results and points depict observations)

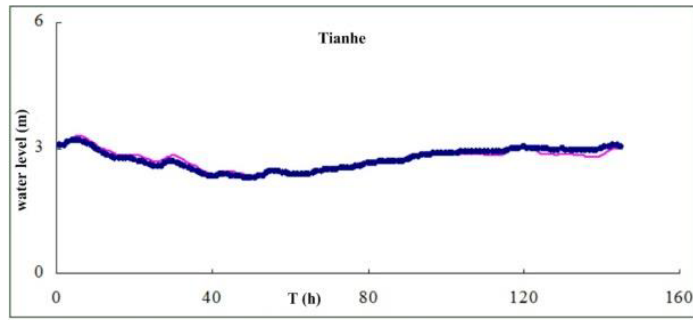

(1)

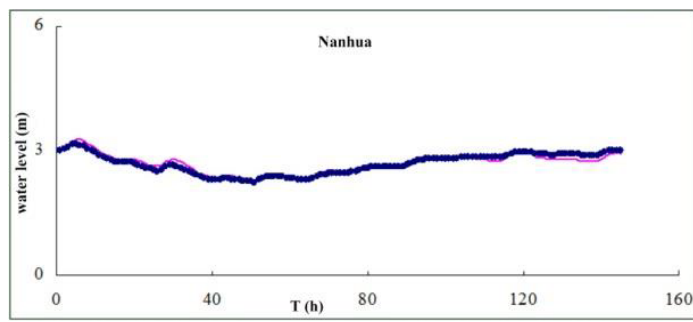

(2)

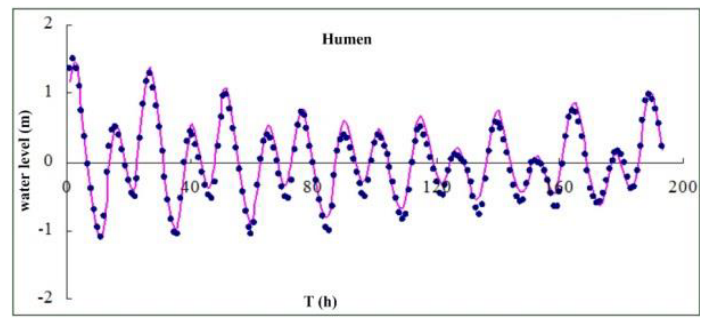

(3)

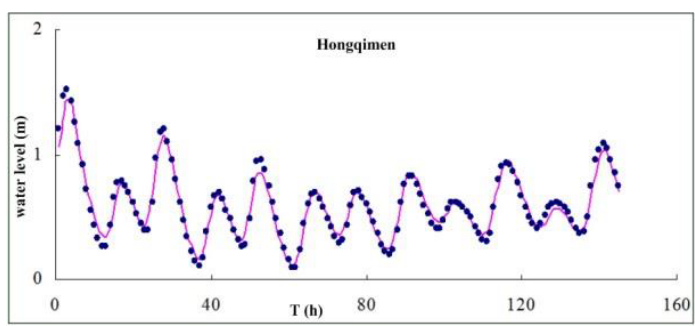

(4)

Figure 2c. Calibration of water level for wet season (solid line signifies model results and points depict observations)

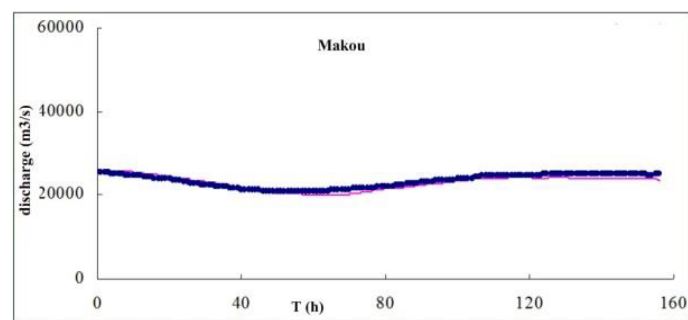

(1)

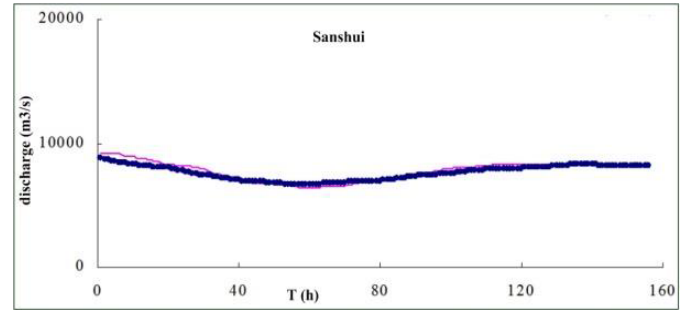

(2)

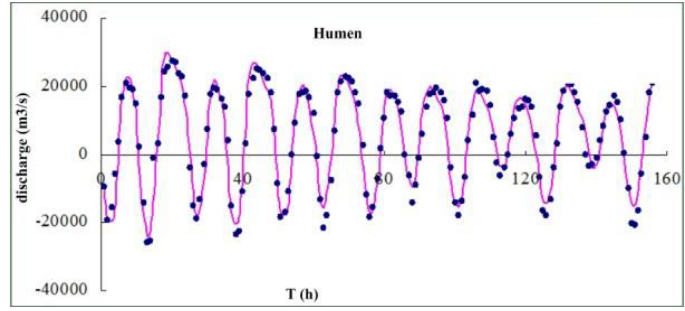

(3)

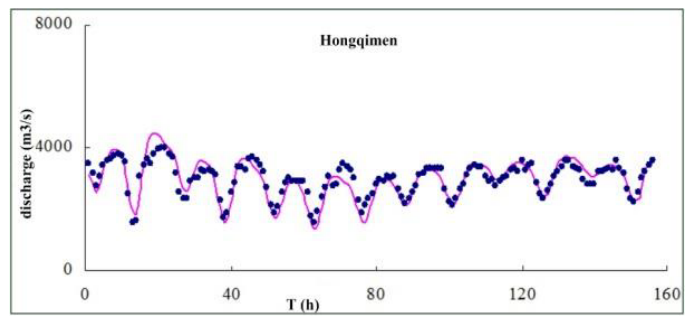

(4)

Figure 2d. Calibration of discharge for wet season (solid line signifies model results and points depict observations)

\section{RESULTS AND DISCUSSIONS}

\subsection{Changes of the divided flow ratio}

The West and North River are the two largest tributaries which account for nearly $90 \%$ of the basin's total drainage area. Fresh water from the two rivers enters the delta via the Gaoyao and Shijiao stations, and then redistributed by the Sixianjiao channel, finally enters the West and North River Main Channel by Makou and Sanshui sections (Figure 1). Therefore, Sixianjiao is the most important divided flow station in the RNPRD. Nearly $80 \%$ of the discharge goes into 

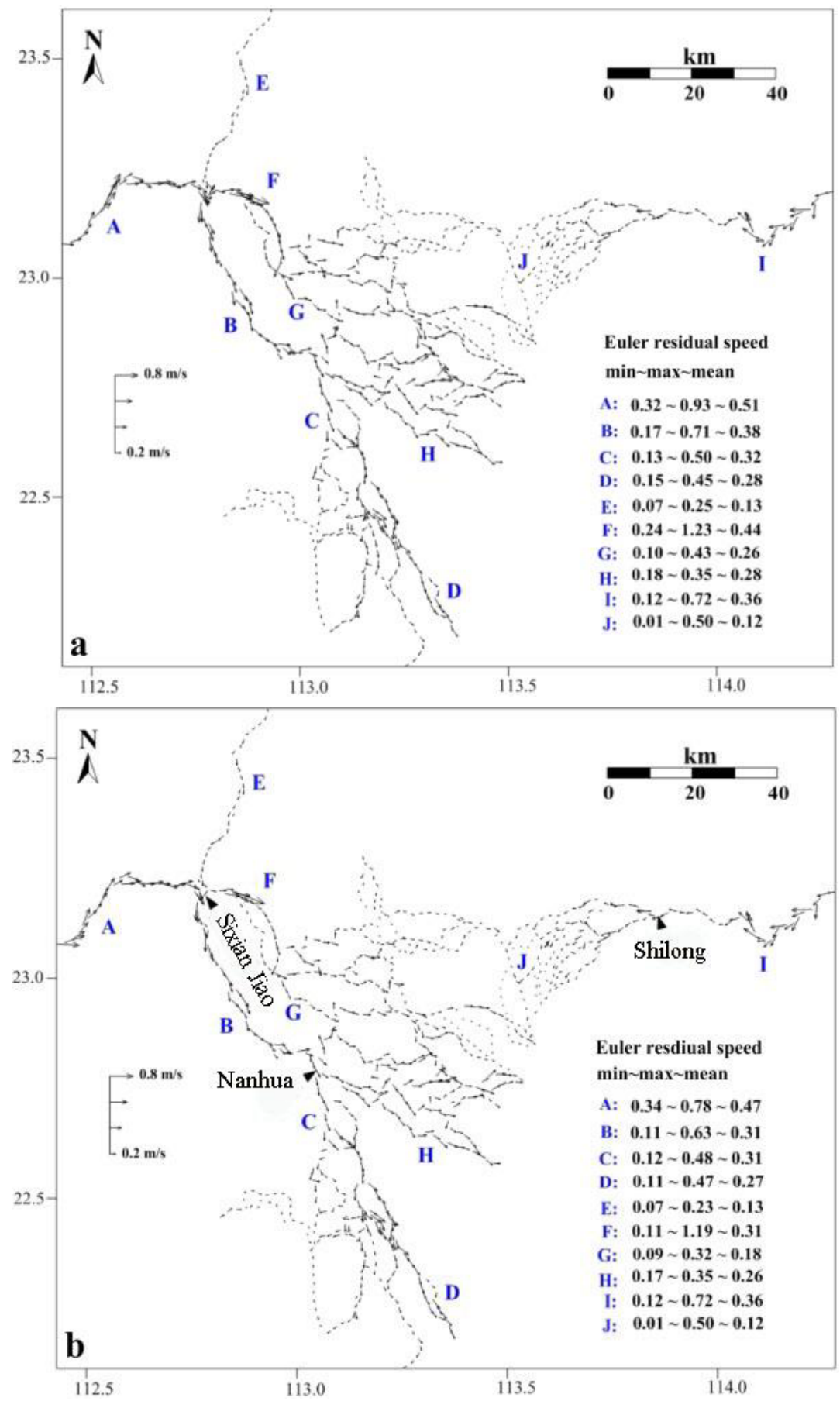

Figure 3. Residual currents for the Pearl River Networks in 2003, under the topography of 1999(a) and 2005(b), (A: West River, B: West River Main Channel, C: Xihai Channel, D: Modaomen Channel, E: North River, F: North River Main Channel, G: Shunde Channel, H: Xiaolan Channel, I: East River, J: East River Delta Networks)

the West River Network though Makou section, and then redistributed again by the secondly station, Tianhe-Nanhua. Hence Tianhe-Nanhua is another major divided flow station.

As shown in Table 3, the annual discharge of Makou station changes from $1614 \times 10^{8} \mathrm{~m}^{3}$ under the 


\section{MATEC Web of Conferences}

topographical condition in 1999 to $1748 \times 10^{8} \mathrm{~m}^{3}$ in 2005 . It means that an extra amount of $134 \times 10^{8} \mathrm{~m}^{3} / \mathrm{yr}$ of fresh water enters the Makou section via Sixianjiao channel due to the abrupt changes of the bathymetry. As a result, the DFR of Makou station has risen from $75.7 \%$ to $82.0 \%$ during 1999 to 2005 , while Sanshui station declined sharply. It is interesting to note that the annual water flux of Tianhe Station increased by $128 \times 10^{8} \mathrm{~m}^{3}$, however, the Nanhua station remained almost the same. This indicated that the extra amount of discharge from Makou station enters the Xihai channel only by Tianhe section. Consequently, during 1999 to 2005, the DFR of Tianhe and Nanhua stations have respectively changed from $54.2 \%$ and $45.8 \%$ to $57.8 \%$ and $42.2 \%$.

Table 3. Annual discharge $\left(10^{8} \mathrm{~m}^{3}\right)$ and divided flow ration (DFR \%) at the Makou-Sanshui and Tianhe-Nanhua stations

\begin{tabular}{lllll}
\hline kTopography & \multicolumn{2}{c}{1999} & \multicolumn{2}{c}{2005} \\
\hline \multirow{2}{*}{ Cross section } & Water & DFR & Water & DFR \\
& flux & flux & \\
Makou & 1614 & 75.7 & 1748 & 82.0 \\
Sanshui & 518 & 24.3 & 384 & 18.0 \\
Tianhe & 825 & 54.2 & 953 & 57.8 \\
Nanhua & 696 & 45.8 & 695 & 42.2 \\
\hline
\end{tabular}

\subsection{Changes of Euler residual flow in the RNPRD}

Figure 3 a shows the mean annual Euler residual flow for the RNPRD under the bathymetry of 1999, which reveals the clear spatial differences in hydrodynamics. The residual flow with high speed are located at the West River Main Channel (B), North River Main Channel (F), Xihai Channel (C), Shunde Channel (G), Xiaolan Channel $(\mathrm{H})$ and Modaomen Channel (D), which are originated from West and North River (called the West and North River Delta Networks). The minimum residual currents are concentrated at the East River Delta Networks (J), starting from the East River. This implies that the runoff plays an essential role in the West and North River Delta Networks such as B, F, C, G, H and D, while the East River Delta Networks (J) is dominated by tidal forces.

Compared with the annual mean residual current in the RNPRD under different terrain conditions (Figure 3. and Figure 4.), it can be noted that the mean residual current significantly decreases in the West and North River Delta Networks. For example, the annual mean residual speed of the West River Main Channel (B), North River Main Channel (F), Shunde Channel (G) and Xiaolan Channel $(\mathrm{H})$ have respectively decreased from $0.38 \mathrm{~m} / \mathrm{s}, 0.44 \mathrm{~m} / \mathrm{s}, 0.26 \mathrm{~m} / \mathrm{s} 0.28 \mathrm{~m} / \mathrm{s}$ to $0.29 \mathrm{~m} / \mathrm{s}, 0.26 \mathrm{~m} / \mathrm{s}, 0.14 \mathrm{~m} / \mathrm{s}, 0.25 \mathrm{~m} / \mathrm{s}$ because the river channel volume of the RNPRD has increased dramatically from 1999 to 2005 due to the large-scale and long-term sand excavation. However, a decrease value of $0.18 \mathrm{~m} / \mathrm{s}$ was discovered only in the North River Main Channel (F), it's much higher than the other studied channels, which could have resulted from both topography and the water discharge. Although the river-bed down cutting occurred in the entire RNPRD, the decreasing trend of the annual mean residual current was intensified in the North River Main Channel (F), while compensated in the West and North River Delta Networks, due to the annual water discharge redistribution of Sixianjiao station. It is interesting to find that the annual mean residual current remained almost the same in the East River Delta Networks (J) in spite of the great changes of the bathymetry. This can be explained as follows: (1) the East River Delta Networks is a relative independent river network, which could not be affected by the water discharge redistribution of the West and North River Delta; (2) the hydrodynamics of the East River Delta Networks are dominated by the tidal forces and the runoff is relatively weak.

\subsection{Changes of fresh water distribution in the eight outlets}

Figure 5 shows the annual fresh water distribution in the eight outlets under the topographical condition of 1999. The annual net discharge volume is up to $623 \times 10^{8} \mathrm{~m}^{3}$ in Modaomen which accounted for $24.8 \%$ of the total runoff, ranking as the first in the eight outlets, while Humen is ranked as the second and accounted for $21.4 \%$. Jiaomen is another major fresh water entrance, which occupied $514 \times 10^{8} \mathrm{~m}^{3}$ of annual total runoff and accounted for $20.5 \%$. The annual water discharges of Hengmen, Hongqimen and Yamen are respectively $301 \times 10^{8} \mathrm{~m}^{3}, 205 \times 10^{8} \mathrm{~m}^{3}$ and $187 \times 10^{8}$ $\mathrm{m}^{3}$, ranking as fourth, fifth and sixth in the eight outlets. Hutiaomen and Jitimen are the minimum amount of discharges, which accounted for only $2.5 \%$ and $3.1 \%$ of the total fresh water discharge.

However, the annual net discharge in Modaomen has increased to $778 \times 10^{8} \mathrm{~m}^{3}$ based on the bathymetry of 2005 , while the other western outlets remained almost the same. For the Eastern four outlets, the annual discharge of Jiaomen, Humen are $408 \times 10^{8} \mathrm{~m}^{3}$ and $481 \times 10^{8} \mathrm{~m}^{3}$, a decrease of $106 \times 10^{8} \mathrm{~m}^{3}$ and $56 \times 10^{8} \mathrm{~m} 3$, respectively, but the discharge of Hengmen and Hongqimen stayed almost stable. As we know, Humen and Jiaomen are located at the top of the Lingdingyang Bay, and the hydrodynamics of these two entrances are dominated by the tidal forces. During the past 20 years, the tidal channels of Jiaomen and Humen are deepened as a result of waterway regulation and uncontrolled sand excavation, so that the tidal waves can be more convenient for us to sail upstream and transport in the river network (Zhang et al., 2010). The runoffs from the upstream of the RPPRD are pushed southwestward by the more powerful tidal forces, which directly reduced the fresh water distribution of Jiaomen and Humen outlets. On the other hand, the fresh water paths in Modaomen dominated by runoffs are also deepened, which draw the water discharge towards Modaomen entrance. Because of the transverse water gradients changes induced by the bottom topography, the annual water discharge distributions of Modaomen dramatically increased while 


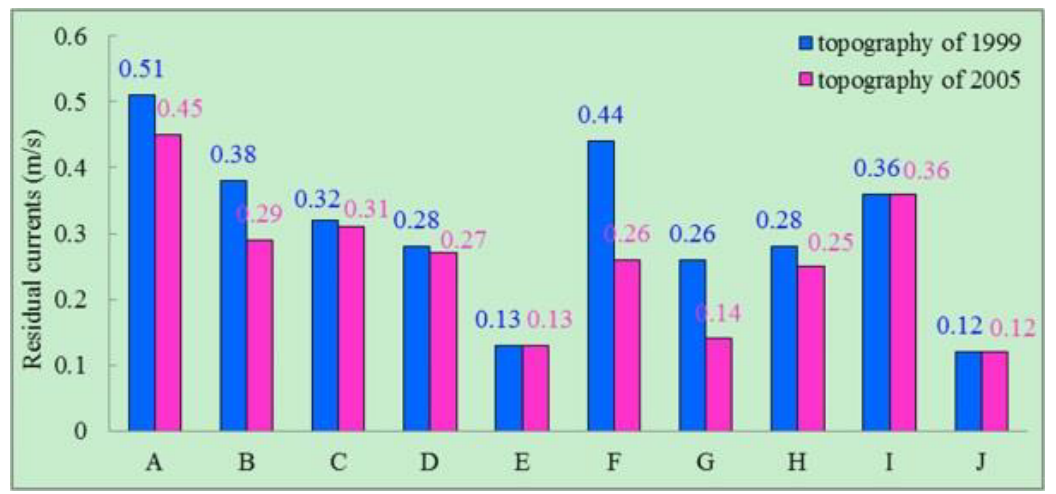

Figure 4. Comparison of residual currents for the major river networks in the RNPRD based on different bathymetries

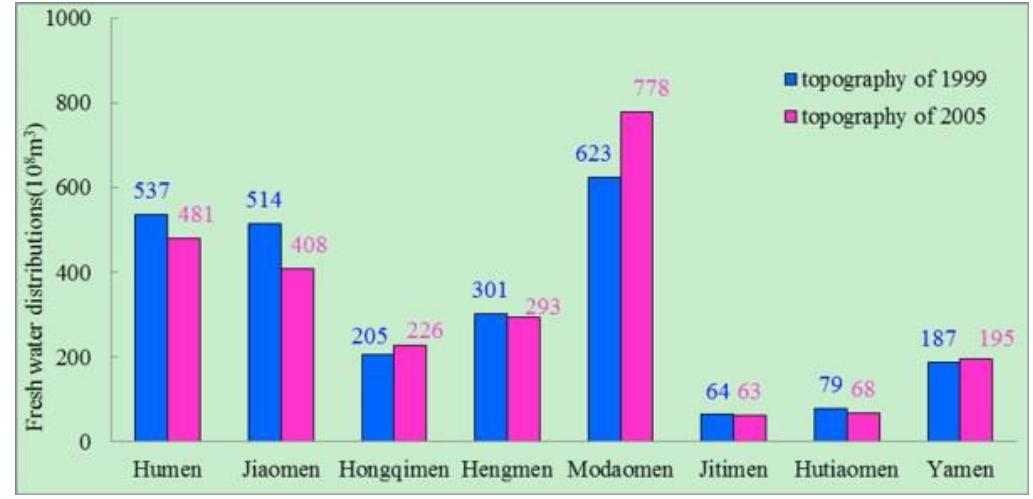

Figure 5. Comparison of water distribution in the eight river outlets based on different bathymetries

the Jiaomen and Humen correspondingly decreased.

\section{CONCLUSIONS}

The fresh water distributions in the Pearl River Network (RNPRD) under different topographies were investigated with a 2-D numerical model, which covered the entire Pearl River Delta. The model results show that although the severe river-bed down cutting occurred in the entire PRD, the water redistribution in the RNPRD is totally different in space and time. The tidal forces from Jiaomen and Humen are strengthened, which pushed the runoffs form the upstream of the RPPRD southwestward, while the deepened water paths of Modaomen draws more fresh water towards the Modaomen outlet. Because of the increased river channel volume of the RNPRD, the annual mean residual speed significantly decreased. However, the decreasing trend was intensified in the North River Main Channel, while compensated in the West River Delta Networks due to the annual water discharge redistribution in the RNPRD.

\section{REFERENCES}

[1] Luo, X.L. \& Zeng, E.Y. \& Ji, R.Y. \& Wang, C.P. 2007. Effects of in-channel sand excavation on the hydrology of the Pearl River Delta, China. Journal of Hydrology: 343(3): 230-239.

[2] Zhang, W. \& Ruan, X.H. \& Zheng, J.H. \& Zhu, Y.L. \& Wu, H.X. 2010. Long-term change in tidal dynamics and its cause in the Pearl River Delta, China. Geomorphology: 120, 209-233.

[3] Luo, X.L. \& Yang, Q.S. 2002. River-bed evolution of the Pearl River Networks. Zhongshan University Press, Guangzhou, China.

[4] Hu, J.H. \& Li, S. \& Geng, B. 2011. Modeling the mass flux budgets of water and suspended sediments for the river network and estuary in the Pearl River Delta, China. Journal of Marine Systems: 188(2): 252-266.

[5] Du, J. \& Zhang, W. \& Mu, S.S. \& Lv, S.J. \& Gong, F. 2014. Response of hydrodynamic on abrupt changes of bathymetry in the Pearl River Delta. International society of offshore and polar engineers (ISOP): 1049-1056.

[6] Hu, J. \& Li, S. 2009. Modeling the mass fluxes and transformations of nutrients in the Pearl River Delta, China. Journal of Marine Systems: 78(1): 146-167. 